Daimon. Revista Internacional de Filosofía, n ${ }^{\circ}$ 76, 2019, pp. 67-77

ISSN: 1130-0507 (papel) y 1989-4651 (electrónico)

http://dx.doi.org/10.6018/daimon/273521

\title{
Tecnotrascendencia como ilusión narcisista
}

\author{
Techno-transcendence as a narcissistic illusion
}

\begin{abstract}
Resumen: Esbozamos en este artículo, para empezar, lo que tal vez habría que denominar una genealogía nietzscheana mínima de nuestra creencia en la inmortalidad personal. A continuación, procuramos interpretar un texto muy relevante de Nick Bostrom, pero solo dirigiéndonos a sus márgenes, a sus lagunas, a lo que quedaría en cierto modo fuera del mismo. Justamente con la intención de mostrar que eso que queda fuera, la cuestión de la inmortalidad, puede ser lo que en último término dé sentido a la totalidad. Para terminar, nos serviremos de dos críticas muy lúcidas de esta desviación del pensamiento posthumanista que podríamos llamar, sin duda, la desviación esencial. Y concluiremos mostrando la necesidad de un posthumanismo que asuma un carácter decididamente crítico.
\end{abstract}

Palabras clave: posthumano, inmortalidad, Nietzsche, Healthspan, crítica.
MARIANO RODRÍGUEZ GONZÁLEZ*

\begin{abstract}
In this paper we get started on sketching what perhaps should be called a minimal Nietzschean genealogy of our belief in personal immortality. Then we will try to interpret a very significant Bostrom's essay, but just by addressing the reading to its margins, its lagoons so to say, to that which would somehow extend outside it. Precisely with the intention of showing that what is apparently outside, the issue of immortality, could be what ultimately gives meaning to the whole. Finally, we will be helped by two very lucid criticisms of this deviation of posthumanist thought that we might call, no doubt, its crucial deviation. So that we conclude by showing the need for Posthumanism to decidedly assume a critical stance.
\end{abstract}

Keywords: Posthuman, Immortality, Nietzsche, Healthspan, Criticism.

Recibido: 20/11/2016. Aceptado: 15/05/2017.

* Universidad Complutense de Madrid. Profesor Titular, Facultad de Filosofía. marian@ filos.ucm.es

Líneas de investigación: Nietzsche y filosofía de la mente. Dos obras representativas de su producción: -"Los buenos mienten siempre. Una lectura de la transvaloración nietzscheana", en Rodríguez, M. (ed.), Nietzsche y la transvaloración de la cultura. Madrid, Arena Libros, 2015. -"Saber de las pulsiones. ¿Sería apropiado hablar de una epistemología nietzscheana?", en Estudios Nietzsche 12, 2012

Este trabajo ha sido elaborado con el apoyo del Proyecto de la DGICT "Obras Completas de Nietzsche en castellano: Obras de madurez tardía y complementos a la edición", referencia FFI2014-53386-P, Programa Estatal de Fomento de la Investigación Científica y técnica de excelencia. 
Orientados en el fondo por ella, aunque intentando estudiar el tema haciendo abstracción de la cuestión de si el pensamiento nietzscheano es o no precursor relevante de la filosofía de lo posthumano - probablemente en ciertas dimensiones sí lo sería, como ha mostrado parte de la obra de S. L. Sorgner ${ }^{1}$ - , damos comienzo a este trabajo haciendo constar la sorpresa que a todo el que se interna en todo este asunto del trans- y del posthumanismo probablemente le provocará comprobar cómo se ha infiltrado en muchos de sus más conspicuos representantes el tan añejo discurso de la inmortalidad personal, a pesar de poderse considerar hoy, a mi juicio, más estrafalario que nunca. Ingenuamente lo podríamos tomar en un principio por una mera excrecencia, un desarrollo marginal, porque en todas las líneas de pensamiento que se van haciendo vigentes, o simplemente se van poniendo de moda, siempre los hay que aprovechan la ocasión para insertar en ellas esta su peculiar obsesión, por lo demás aún tan extendida. Pero, en un segundo momento, la relevancia que han adquirido para el marketing "filosófico" del transhumanismo las reflexiones de ingenieros y científicos tales como el célebre Ray Kurzweil o el quizás más famoso Aubrey de Grey-y digo reflexiones en el sentido corriente, porque el discurso de los ingenieros, con su pretensión de limitarse a relatar hechos y a hacer pronósticos, no me parece que se pueda considerar en sentido estricto un discurso filosófico-, tal vez nos debiera llevar al convencimiento de que la ilusión de la inmortalidad personal no ocuparía en absoluto un lugar secundario o una función accesoria en todo este asunto. Con ello, nuestra decisión es la de situarnos en una posición abiertamente crítica frente a la infiltración de semejante fantasía, por mucho que filósofas tan críticas como R. Braidotti eviten en el fondo hacerlo abiertamente, limitándose a expulsarla a un lugar completamente exterior, marginal, y por lo tanto insignificante. Cuando a nuestro parecer no lo sería en absoluto, por mucho que sea evidente que no todos los pensadores y pensadoras de lo posthumano participan, ni muchísimo menos, de esta desviación personalista a que pretendemos oponernos en este trabajo, sirvan de ejemplo los ya citados Sorgner y Braidotti. Pero, en cualquier caso, si es cierto que se trata de una cierta desviación respecto de la regla, como decimos, lo que sí nos gustaría mantener aquí es que nos hallamos, con ella, ante lo que se puede considerar la desviación esencial, y por eso es nuestra opinión que resultará muy conveniente reforzar el talante crítico del posthumanismo.

1 Lo que sin duda sería mucho más discutible es que se pueda presentar legítimamente a Nietzsche como de alguna manera precursor del transhumanismo, o, para ponerlo con otras palabras, si encajaría en el espíritu de la letra nietzscheana considerar verosímil la posibilidad de ir más allá de lo humano, de superarlo hacia el Übermensch, precisamente por la vía que nos abre la tecnociencia. Sorgner también habría venido defendiendo lo que él mismo denomina un transhumanismo nietzscheano en sentido débil, desde su intervención, que le hizo célebre, en el debate internacional a que dieran lugar sus artículos publicados en el Journal of Evolution and Technology (por ejemplo, "Nietzsche, the Overman, and Transhumanism", Vol. 20, Issue 1, March 2009, 29-42 págs., o también, "Beyond Humanism: Reflections on Trans- and Posthumanism”, Vol. 21, Issue 2, October 2010, 1-19 págs.). Recientemente ha desarrollado el mismo Sorgner sus puntos de vista sobre este asunto, más elaborada y justificadamente, en su libro Transhumanismus - “die gefährlichste Idee der Welt”!?, Freiburg, Basel und Wien, 2016. Por otra parte, cuando redactamos estas líneas se está a la espera de recibir en las librerías la obra editada por Yunus Tuncel, cofundador del neoyorkino Nietzsche Circle, con el título de Nietzsche and Transhumanism. Precursor or Enemy?, Cambridge Scholars Publishing, 2017, en la que dilucidarán la cuestión algunos de los representantes más destacados de los estudios nietzscheanos en lengua inglesa. 
No podemos dejar de reconocer, por nuestra parte, que esta conclusión sería también algo así como una huella filosófica de determinadas experiencias personales: pienso sobre todo en uno de los congresos internacionales que se organizan periódicamente sobre cuestiones trans- y posthumanistas, porque durante su transcurso me quedé verdaderamente perplejo al comprobar la abrumadora presencia de teólogos, y las numerosas mesas redondas organizadas donde se iba a discutir apasionadamente la cuestión de la inmortalidad, como si se tratara de un objetivo milenario de la humanidad, ahora de consecución inminente. ¡Pero mi perplejidad quedó en muy poco comparada con la de un teólogo polaco cuando advirtió que a mí el tema no me interesaba en absoluto!

\section{Inmortalidad personal}

Ese Nietzsche que, de alguna manera, y sin que vayamos a forzar demasiado el sentido de su pensamiento, podríamos caracterizar de "posthumanista", reconocerá que es indispensable llegar a la "máquina", esto es, al cálculo, a la robotización diríamos nosotros hoy, para que el resultado de esta civilización tecnocientífica que va siendo la nuestra cada vez en mayor medida, y probablemente sin que podamos evitarlo, una civilización que sin duda nos convierte a nosotros mismos en máquinas, nos traiga a todos nosotros el sentimiento del más profundo y desolador hastío. Justamente porque después del hastío llegará, cuando menos para algunos, el salto a lo totalmente otro, la liberación. Llegará la liberación, en efecto, para aquellos que sepan encontrar su placer en el sinsentido del mal, o sea, del azar, de lo incierto, lo imprevisto. Esto significa precisamente aquello que el filósofo alemán llamará, resumiéndolo todo, pesimismo de la fuerza. Habremos tenido que domar la suerte ${ }^{2}$, computándola, sometiéndola a golpe de algoritmo, porque solo después, únicamente así, podremos dar el salto a la alegría de lo real no computable. Esta tecnotrascendencia nietzscheana es la trascendencia inmanente de la vida como voluntad de poder, y la del Übermensch, en lo que a nosotros atañe, trascendencia inmanente del sentido de la Tierra que exige como conditio sine qua non la muerte de todos los dioses, incluidos por supuesto la ciencia como Dios y la tecnología como Dios.

Ahora bien, toda la historia de la cultura representa una disminución de ese temor al azar, a lo incierto, a lo imprevisto. Cultura quiere decir, precisamente, aprender a calcular, aprender a pensar causalmente, aprender a prevenir, aprender a creer en la necesidad. Con el crecimiento de la cultura el hombre puede prescindir de esta primitiva forma de sometimiento al mal (llamada religión o moral), de esa «justificación del mal». Ahora le hace la guerra al «mal»-- lo elimina. Es posible incluso un estado de sentimiento de seguridad, de creencia en la ley y la calculabilidad en el que éste aparece a la conciencia en forma de hastío,- en el que emerge como una excitación el placer del azar, de lo incierto y de lo imprevisto...

Detengámonos un instante en este síntoma de suprema cultura-lo llamo el pesimismo de la fortaleza. ${ }^{3}$

2 Tomando la expresión de J. Elster, Domar la suerte, Barcelona, Paidós Ibérica, 1991.

3 NF-1887, 10 [21], FP IV, 304-305 págs. KSA 12, 466-467 págs. (Fragmentos Póstumos 1885-1889, edición española dirigida por D. Sánchez Meca, Madrid, Tecnos, 2006. Friedrich Nietzsche Sämtliche Werke. Kritische 
Es la cultura más elevada la de este pesimismo de la fortaleza, que nada tiene que ver, sino que incluso representa todo lo contrario de la tradicional creencia en la inmortalidad personal, con su remoto origen en las religiones mistéricas de la antigua Grecia por lo que a nuestra historia occidental se refiere. «Pero en todo el mundo, donde hubo cultos secretos se dio también esa creencia en la duración continuada, y ciertamente bajo la perspectiva de la recompensa y el castigo» ${ }^{4}$, escribe Nietzsche ese mismo año, en un apunte dedicado a Pablo de Tarso, y a la paulina contraposición de la vida verdadera y la vida falsa, en el fondo tan antijudía y anticristiana, en opinión del filósofo, que el apóstol iba a recuperar de lo más sombrío del paganismo. Para la religión homérica, en cambio, una religión abierta o pública, diurna, esta creencia mistérica era la muestra de un desenfreno, un vicio, un desatino, un pecado contra Apolo: "nada en demasía", es preciso mantenerse dentro de los propios límites. En uno de sus últimos y más sorprendentes fragmentos, Nietzsche concuerda de todo punto con el mandato apolíneo, desde su perspectiva de la transvaloración de todos los valores, cuando declara, tal vez parodiando las célebres palabras de Jesús, que él nos trae la guerra, pero una guerra que hay que entender únicamente como "guerra contra el vicio" o el libertinaje espiritual que encarnaría, según él, el sacerdote cristiano ${ }^{5}$. En lo que a nosotros concierne en este trabajo, resulta de todo punto impensable o inconcebible, rozando el delirio, a su juicio, la supuesta idea de "este" Pablo o "este" Pedro, existiendo con duración ilimitada, por toda la eternidad. Además, para empezar, ¿quién es Pablo o Pedro? Con su práctica vital, el mismo Jesús, el único cristiano existido, había dejado ya atrás toda la ridiculez de la idea de persona ${ }^{6}$. Porque la idea de persona resulta, en el fondo, ridícula, podemos decir que igual de ridícula que el trastorno narcisista de la personalidad: el pensamiento de "la salvación de mi alma", la única cosa necesaria, para el movimiento cristiano de Pablo, es el mismo pensamiento de que el mundo, en su totalidad, gira a mi alrededor, como si no tuviera otra cosa que hacer. Todo lo contrario, lo que nietzscheanamente conviene es ir por encima, o superar, tanto el yo como el tú, es decir, hay que llegar a «sentir cósmicamente» ${ }^{7}$.

Tampoco el judaísmo, ni, para Nietzsche, el único cristiano que ha habido, tendrían nada que ver con esta creencia de la inmortalidad de la persona. Desde el universo griego, ya Epicuro había dirigido buena parte de sus esfuerzos filosóficos a liberar a los ciudadanos del terror que en muchos de ellos ocasionaba semejante idea. Pero el apóstol Pablo organizó el cristianismo político en torno a la esperanza en la resurrección de la carne, con lo que a juicio de Nietzsche entronizó el disparate y la desvergüenza en la cultura occidental subsiguiente. Ahora va a resultar que la verdadera vida es la vida eterna, o sea, justamente lo contrario de la vida, la no-vida.

Studienausgabe in 15 Bänden hgn. von G. Colli und M. Montinari, Berlín / Nueva York, Walter de Gruyter, 1980).

4 NF-1887, 11 [281], FP IV, 437. KSA 13, 108.

5 NF-1888-9, 25[1], "La gran política", FP IV, 774. KSA 13, 638.

6 NF-1887-8, 11 [354], FP IV, 466. KSA 13, 154.

7 Cf. NF-1881, 11 [7], FP IV, 760. KSA 9, 443. 


\section{El secreto al descubierto}

Así que no nos cabe duda de que la supuesta idea de la inmortalidad personal - y escribo "supuesta" porque en el fondo no se sabe bien si es una idea de verdad coherente, con un sentido especificable - , la tenemos que rechazar por las razones expuestas, pero este rechazo no le quitaría nada de su posibilidad, por lo menos a primera vista, ni de su hipotético atractivo, a la perspectiva tecnocientífica de una prolongación muy notable, en verdad hasta espectacular, del periodo de vida en que podamos mantenernos sanos y jóvenes - si bien, en principio, habría que decir que sería solo "hipotético" este atractivo, porque no queda excluida la posibilidad de que entonces, por ejemplo, a lo peor enloqueceremos de aburrimiento, aunque también se pueda pensar, con razón, que solo se aburren los tontos, como el mismo Bostrom nos da a entender con la sugerencia de que, para eludir la amenaza del aburrimiento en una vida sin final previsible, habría que implementar programas de mejora cognitiva para todos, que nos permitieran ser felices dedicados a conocer más y más. En cualquier caso, por lo menos parecería que una de estas creencias es hoy perfectamente razonable, la creencia en la posibilidad del extended healthspan. Pero en este punto tan vital no es muy retorcido llegar a entrever, leyendo atentamente su trabajo, que un autor de la talla del mencionado Bostrom acaba traicionándose al llegar a cierto momento de su escritura, y al hacerlo también traiciona un secreto de gran dimensión, verdaderamente mistérico. En uno de sus textos más relevantes en relación con el tema que aquí discutimos ${ }^{8}$, nos escribe, bien es verdad que entre paréntesis, como si la cuestión no tuviera apenas importancia o hubiera que darla por supuesta, que, según su modo de ver, están equivocados los que piensan que la mortalidad o el envejecimiento serían "de algún modo rasgos esenciales de las personas que nosotros somos". De modo que el posthumano, podríamos ir sospechando a partir de esto, es posible que se configurase como una especie de superhombre, pero justamente en la medida que de algún modo tuviera la inmortalidad al alcance de la mano (un auténtico homo deus, dicen algunos de los más entusiastas). Se trata de la salvación por la tecnología, en definitiva, y por si esto fuera poco, la más tradicional de las salvaciones, que es la salvación de la muerte.

Porque hay que reparar, para empezar, en esta igualación tan notable que establece Bostrom, tan supuestamente aproblemática, la mortalidad o el envejecimiento: suspender éste significaría entonces, propiamente, "matar la muerte". Pero esto quiere decir propiamente que, para Bostrom, nosotros los humanos no somos en absoluto "los mortales" de los griegos antiguos, como diferentes y opuestos a los dioses inmortales, sino que seríamos

8 Nick Bostrom, "Why I want to be a Posthuman when I Grow Up", in Medical Enhancement and Posthumanity, eds. Bert Gordijn and Ruth Chadwick, Springer, 2008, págs. 107-137 (publicado en borrador ya en 2006), y disponible también en la web de Bostrom. En este escrito programático el director del Instituto del Futuro de la Universidad de Oxford defiende sin ambages la deseabilidad, por lo menos para algunos seres humanos, del desarrollo por la vía tecnológica de capacidades que podríamos considerar posthumanas, justamente aquellas imposibles de lograr por medios simplemente "naturales", sobre todo de aquellas directamente relacionadas con la prolongación de la vida activa y sana que podríamos disfrutar en principio, en primer lugar, pero también con la plena lucidez cognitiva mantenida asimismo "artificialmente", por así decir, y asimismo las que nos asegurarían una existencia satisfactoria y feliz en el nivel emocional implicado en las relaciones sociales. Las dos últimas se hallarían, como es obvio, estrechamente relacionadas la una con la otra, si bien también tendrían mucho que ver con la primera, que por supuesto es la que aquí nos concierne más directamente. 
verdaderos dioses, solo que «con prótesis», por usar aquí de nuevo la famosa expresión de Freud $^{9}$. Porque está claro que para ser dioses con prótesis nuestra naturaleza, en el fondo, en absoluto podría ser mortal, puesto que toda naturaleza implica la fijación de unos límites infranqueables, y la muerte ya no es límite ninguno para nosotros, en el sentido preciso de que el envejecimiento o la muerte no sería en absoluto inevitable. La «singularidad» que estaría ya tan cerca ${ }^{10}$ conlleva por tanto la trascendencia como tecnotrascendencia, desde el momento en que el software biológico, como todo software, se puede modificar, sustituir, o conectar con otro software. Se trata de la informática devenida biología, o a lo mejor viceversa, paradigmáticamente en la obra de un investigador tan en la cresta de la ola como de Grey ${ }^{11}$.

Con todo ello lo que se revela es que la misma condición de posibilidad de todo el proyecto, constitutivo del trans- y del posthumanismo, de la prolongación de la vida hábil es el mismo límite ideal que pone la creencia, más bien la fantasía, de la inmortalidad personal. La muerte, entonces, y esto no es de ninguna manera ninguna novedad, no dejaría de ser degradada a accidente, mera casualidad explicable por las circunstancias siempre azarosas que concurren en el caso del fallecimiento concreto, pero en absoluto algo consustancial a la vida ${ }^{12}$. Heráclito estaba completamente equivocado, en definitiva, cuando identificó tan sabia pero enigmáticamente a Dionisos dios de la vida con Hades dios de la muerte ${ }^{13}$. Envejecemos simplemente porque todavía no ha llegado el año 2045, dicen, y no son pocos, envejecemos ahora, pero solo porque hemos tenido la mala suerte de nacer antes de ese año (en el supuesto, claro está, de que si nacemos después tengamos suficiente dinero para hacer frente al coste de los diversos tratamientos).

Sin duda será una transformación radical la que nos haga posthumanos, pero de cualquier modo esa transformación tiene que venir posibilitada por un potencial de inmortalidad precedente que el desarrollo tecnocientífico se limitaría a actualizar, si lo podemos decir así, y Bostrom, en este punto, termina de poner las cartas sobre la mesa cuando la compara, a esta transformación, con la escatología de la creencia religiosa tradicional, la transformación radical que tendría lugar después de esta existencia física que llevamos por el momento. Recuperamos la vida eterna en el momento en que superamos nuestra condición accidental

9 Cf. Freud, S., El malestar en la cultura, III, Madrid, Biblioteca Nueva, 1999, pág. 85. El optimismo tecnocientífico de entonces se compensaba con un decidido pesimismo en cuanto a las disposiciones "morales" de los humanos. En Freud, por ejemplo, esto se echaba de ver en todo lo relativo a la gestión de la llamada pulsión de muerte. En el transhumanismo actual, en cambio, se entrega a la tecnociencia el diseño completo de la vida humana, también en el sentido de la mejora moral y socio-política, que solo se tendría que enfrentar a problemas técnicos y por tanto en principio resolubles.

10 Cf. Kurzweil, R., The Singularity is Near. When Humans Transcend Biology, London, Viking Penguin, 2005. La cuestión ha dejado de ser la tan amenazadora del oscuro panorama de los robots sublevándose contra los seres humanos al que se refería Hawking. Ahora lo que nos presentan todos estos optimistas de la omnipotencia tecnológica son las infinitas y halagüeñas posibilidades de la fusión del humano con la máquina.

11 Cf. A. de Grey y M. Rae, Ending Aging: The Rejuvenation Breakthroughs that could reverse Human Aging in Our Lifetime, Nueva York, St. Martin's Press, 2008, entre otras obras. Atiéndase a lo significativo de este título para nuestro tema.

12 Habitual estrategia de negación que resultó por una vez inviable a la vista de la "acumulación de muerte" que nos trajo la Gran Guerra. Cf. Freud, S., "Consideraciones de actualidad sobre la guerra y la muerte", en El malestar en la cultura. Madrid, Alianza Editorial, 1970, págs. 96-124.

13 Fragmento 15 (Diels-Kranz). 
de seres caídos. Por si esto fuera poco, en la nota 41 del escrito al que me vengo refiriendo, se conecta ya abiertamente la búsqueda de capacidades posthumanas con la búsqueda de la inmortalidad, en la misma línea, por ejemplo, de los exploradores que iban en pos de la fuente de la eterna juventud, o de los alquimistas lanzados tras el elixir de la vida. La única diferencia sería el pequeño detalle, pero indudablemente importante, de que con las religiones tradicionales la esperanza de esta existencia posthumana, absolutamente otra, pero reclamada por nuestra verdadera naturaleza humana, se hallaba por supuesto vinculada con la creencia en lo sobrenatural. Las tecnologías NBIC habrían ocupado en nuestros días el lugar de semejante creencia del modo más limpio y realista posible. Realizamos efectivamente la promesa de la salvación, pero ahora sin necesidad de enredarnos en ningún laberinto místico de los de antes.

\section{Ideal ascético}

De manera similar a como Nietzsche desenmascaró el espíritu que anima a la ciencia moderna, poniendo al descubierto su mística peculiar, el ideal que la guía, como nada más que el último vástago y el último avatar del ideal ascético, y eso en contra de todas las apariencias, en nuestros días la filósofa Babette Babich, estudiosa de la obra nietzscheana, pretende presentarnos lo que ella llama el sueño del transhumanismo como la última versión, a la que sin duda seguirán otras, de ese mismo ideal ${ }^{14}$. Llegar a ser posthumano no significa de ningún modo llegar a ser el que se es, sino, antes al contrario, llegar a ser como deseas ser o te imaginas ser, en tu imperturbable y "omnipotente" wishful thinking. Ninguna novedad real, pues, de lo que se sigue tratando es de engañarse a uno mismo, o de "ilusionarse".

Se dispondría por tanto el transhumanismo en la senda viejísima de la línea dominante de toda la cultura occidental, por no decir planetaria: el nervio de la cuestión por supuesto está en que queremos la vida, pero no ésta. Queremos la vida, pero sin sufrimiento, enfermedad, vejez, la vida absolutamente limpia de muerte. O sea, queremos OTRA vida, radicalmente otra, antitética de la que vivimos, lo que queremos, en suma, es estar en otro sitio. Pero el caso es que se trata de un sitio en realidad imposible. Un lugar que viene a ser, en realidad, como la nada pura y dura. Por eso Nietzsche caracterizaba esencialmente el ideal ascético como simple voluntad de nada ${ }^{15}$. Pero ocurre que en nuestro tiempo hemos atisbado por fin la posibilidad tan cercana del salto mortal de la trascendencia ("matar la muerte": trascender

14 B. Babich, "Nietzsche's Post-Human Imperative: On the 'All-too-Human' Dream of Transhumanism", en The Agonist. Vol. IV, Issue II (2012). (http://www.nietzschecircle.com/AGONIST/2011 08/Dream of Transhumanism.html). Este escrito constituye la intervención de Babich en contra de la línea de Sorgner que intenta aproximar el transhumanismo a determinadas figuras importantes del pensamiento nietzscheano. No por casualidad la pensadora norteamericana se habría distinguido como especialista en la filosofía de la ciencia del filósofo alemán.

15 Como es bien sabido, Nietzsche dedica el Tratado Tercero de su Genealogía de la Moral a intentar responder a la cuestión que él mismo se plantea del significado de los ideales ascéticos. La clave de su respuesta aparecer ya en el primer parágrafo: "Ahora bien, en el hecho de que el ideal ascético haya significado tantas cosas para el hombre se expresa la realidad fundamental de la voluntad humana, su horror vacui: esa voluntad necesita una meta-y prefiere querer la nada a no querer" (Madrid, Alianza Editorial, 1972, pág. 114). Pero como el pensador alemán está seguro de que de entrada no se le ha entendido, o no se le ha podido entender, desarrolla a continuación todo el riquísimo tratado tercero, para concluir al final del libro, en el parágrafo 28 , exactamente 
la biología, nuestra carne reducida a algoritmo). El tradicional desprecio del cuerpo, una vez más, recordemos el célebre discurso de Zaratustra-porque el cuerpo invariablemente enferma, duele y envejece, incluso los hay feos y desagradables, con todos sus malolientes humores, orines, excrementos, en lo que ya insistían los obispos medievales - , ese mismo desprecio que se traduce hoy y se disfraza nada más y nada menos que de anhelo de ser robot o de mezclarnos íntimamente con la metálica y erotizada pseudocarne de robot. En cualquier caso, lo que queremos es un cuerpo que se pueda actualizar cuando lleguen las últimas novedades en el campo de las aplicaciones, un cuerpo que admita recambios sin límite, recomposiciones, renovaciones y sustitución de piezas cuando empiecen a fallar las que vienen de serie. Eso sí, se plantearán nuevos retos para la reflexión: en la $\mathrm{BBC}$, por ejemplo, se da noticia de que un filósofo moral de la IA nos advierte contra el uso de los robots para el sexo porque ello implicaría la degradación de la mujer.

Babich nos dice que, en nuestro ahora, la salvación, la redención, como transfiguración tecnológica de la carne, encontraría su posibilidad más propia no ya en una existencia ética en el sentido de obediente a los mandamientos del señor Dios, no ya en hacer la voluntad del señor Dios en lugar de la tuya o como si fuera de verdad la tuya, sino simplemente en el dinero. Porque si solo el progreso tecnológico garantiza mi salvación o mi acceso a la transformación radical que será la vida OTRA, vida limpia, purgada de muerte, entonces aquello en lo que tenemos que reparar inmediatamente es en el hecho incontestable de que el progreso tecnológico sería simplemente cuestión de dinero. De modo que, apunta la pensadora norteamericana, hemos vuelto de nuevo a la cuestión crucial de los ricos y los pobres. Ya no salva Cristo, lo que salva es el dinero. ¿Y quién va a dudar de esto hoy, en el fondo? Lo nuevo es aquí la salida de tono del que afirma sin ningún rubor que el dinero da la vida eterna, lo cual puede parecer, sin embargo, una conclusión lógica para todo el desarrollo histórico al que hemos venido asistiendo desde el nacimiento del Capitalismo.

\section{Posthumanismo crítico}

El progreso de nuestra reflexión, no solo a partir del estado actual del conocimiento sino sobre todo considerando las transformaciones de la vida cotidiana, nos habría instalado, a la altura de nuestra época cultural, en la llamada condición posthumana. Vacío de sentido se halla hoy cualquier modelo definido de ser humano en sus mismas pretensiones totalizadoras, habiendo explotado desde dentro de ese concepto violentamente unificador las múltiples diferencias que nos habitan, por ejemplo, en cuanto a lo sexualizado y lo racializado. En primer lugar, porque se han ido borrando cada vez en mayor medida los límites, otrora tan nítidos e indiscutibles, que separaban animalidad y humanidad, por un lado, y los límites entre humano y máquina, por otro ${ }^{16}$. En segundo término, porque el sujeto autoidéntico se

del mismo modo: "Y repitiendo al final lo que dije al principio: el hombre prefiere la nada a no querer" (pág. 186). Y esta vez sin duda se le entiende.

16 De modo que se haría muy conveniente, cuando no necesario, replantear la irrenunciable cuestión de la dignidad humana desde esta nueva situación nuestra; en definitiva, el planteamiento de una dignidad posthumana. Cf. para todo este importante asunto las aportaciones de los diversos autores que se dan cita en la obra editada por Beatrix Vogel, Umwertung der Menschenwürde-Kontroversen mit un nach Nietzsche. Mit einem Vorwort von Michael von Brück. Friburgo / Múnich, Verlag Karl Alber, 2014 (2a). Escrito tomando como eje el 
habría revelado, ya con toda claridad y a partir de la subversión nietzscheana de lo Uno, la llamada «muerte de Dios», nada más que como un mito antaño muy poderoso, y eso tanto en su versión propiamente metafísica como en la trascendental. Muerte de Dios que es a la vez, por supuesto, la foucaultiana muerte del hombre, y, en suma, asimismo la de la "cosa". Y es que, sin duda, hoy tenemos que hablar de procesos en vez de "sustancias", así como del principio del continuo y de las continuidades plurales, en definitiva, de adualismo, si lo queremos decir con Abel ${ }^{17}$, en suma de subjetivización no-una, si lo queremos decir con la Braidotti más deleuzeana ${ }^{18}$, para mentar el lugar ahora vacío donde tradicionalmente se asentaba, indiscutible, la unidad inalterable de la identidad personal. No solo no hay identidad ninguna, sino que esto mismo, la imposibilidad de la identidad, en absoluto importaría ${ }^{19}$.

En otro orden de cosas, pero muy próximo, el de la percepción, y la misma cognición en general, los pensadores de las ciencias cognitivas nos enseñan que son, en todo caso, encarnadas, situadas, extendidas ${ }^{20}$, con lo que la res cogitans cartesiana se habría revelado al fin y al cabo un mito moderno que tiene que desaparecer de nuestro horizonte forzosa y definitivamente. Lo que llamamos "mente" es contextual de manera constitutiva, es decir, siempre relativa a un lenguaje y a unas prácticas por esencia públicos, como Wittgenstein dejó fuera de duda.

De modo que la conclusión para nuestro tema no puede ser sino esta: si el posthumanismo filosófico ha de consolidarse como la concepción sólida y convincente de nuestra situación actual, tendrá que reformularse necesariamente como posthumanismo crítico. Es decir, habrá de preguntarse quiénes somos nosotros en nuestra condición posthumana. Lo que es lo mismo que decir, en lo que hace a la cuestión planteada en este trabajo, que habrá de desterrar las demasiado tradicionales fantasías de trascendencia que han venido latiendo, y al cabo aflorando, no solo en sus márgenes sino en su mismo núcleo, como veíamos. La ilusión actual de la tecnotrascendencia, tan oportunistamente aprovechada por los intereses mercantiles que no dejan de estar atentos a toda ocasión, no puede sobrevivir, valga la ironía, a la crisis de la cuestión del sujeto o de la subjetivización tal y como se plantea en nuestro presente filosófico. Porque, para repetirlo en pocas palabras, ¿quién es el que vivirá "eternamente"? ¿Quién es el que trascenderá la biología? Su mismo sinsentido brota con evidencia de la absoluta falta de respuesta a esta pregunta. Cierto es que la inmortalidad por la vía tecnológica no es la misma inmortalidad que la tradicional de las religiones, pero comparte con ella, no obstante, su absoluta inconcebibilidad en sentido estricto o "metafísico"21.

nietzscheanismo débil de Sorgner, a favor y en contra del mismo, este libro parte del convencimiento del papel central que corresponde al pensamiento del filósofo alemán en el debate del trans- y posthumanismo.

17 Generalizando, como en mi opinión resultaría perfectamente lícito, las conclusiones a las que llegó G. Abel en su fundamental estudio de la "filosofía de la mente" nietzscheana: "Bewusstsein-Sprache-Natur: Nietzsches Philosophie des Geistes", en Nietzsche-Studien: Internationales Jahrbuch für Nietzsche Forschung, 30, 2001. $1-43$.

18 Cf. R. Braidotti (2013), Lo Posthumano, Barcelona, Gedisa, 2015.

19 Cf. D. Parfit (1984), Razones y personas, Madrid, Antonio Machado Libros, 2004.

20 Cf., por ejemplo, entre muchos otros, Varela, F.J.; Thomson, E. y Rosch, E., The Embodied Mind. Cognitive Science and Human Experience, MIT Press, 1991. Chalmers, D.; Clark, A., "The Extended Mind", en Analysis, 58: 1, 1998, págs. 7-19. Noë, A., Action in Perception, MIT Press, 2004.

21 Por otra parte, si lo que se quiere es emplear la imaginación para explorar las posibilidades digamos razonables, convendría leer la asombrosa novela de José Saramago, Las intermitencias de la muerte (Madrid, Alfaguara, 
Queremos que quede claro que esta conclusión nuestra no tendría absolutamente nada que ver con el hábito cultural de hacer del pensamiento de la muerte el centro de referencia de todo movimiento cultural, aquello que la llamada necropolítica consagra en sus perfiles más siniestros. Seamos vitalistas, por supuesto, pero siendo conscientes de que nuestro concepto de la vida como zoé no puede ser tan ingenuo que pretenda ignorar que vida y muerte se pertenecen la una a la otra "por naturaleza", de manera que la vida sería insostenible sin el trabajo letal de la parte maldita.

En relación con nuestro asunto, el posthumanismo crítico pone de manifiesto, por otra parte, la inevitable complicidad de la insensata fantasía de la inmortalidad como tecnotrascendencia con el individualismo neoliberal que vuelve a insistir, siempre que puede, en lo legítimo del beneficio y en lo natural de una existencia planificada sobre el afán de lucro. En el sentido de que los sueños de inmortalidad por vía tecnocientífica no serían hoy otra cosa que delirios de control absoluto de la vida y de la muerte, esto es, pura biopolítica y pura necropolítica en el peor sentido de estos términos, en lo que ha insistido la misma Braidotti: poder disponer por fin de zoé y thánatos para someterlos a la lógica del beneficio. Nietzscheanamente pensado, nuestro inevitable valorar habrá de volcarse, en cambio, sobre la fugacidad incontrolable, sobre lo pasajero de la vida. Una transvaloración radical heredada también por Freud, para quien la vida no es de verdad vida si no pone en juego continuamente la posibilidad de la muerte. En una palabra, nuestra valoración positiva ha de volcarse en la temporalidad de la que estamos hechos, lo que Severino llamaba "el sentido griego del devenir" 22 y que para él era inconcebible, justo al revés de lo que nos ocurre a nosotros. Temporalidad que solo la muerte compendia y representa. Para utilizar la expresión que toma Braidotti, deberíamos reivindicar, en definitiva, "el orgullo de la carne", porque solo así compensaremos el deseo de ser cableados. Solo así será el nuestro un posthumanismo cabal, o sea, no tecnofóbico pero tampoco tecnoeufórico, es decir, "materialista" y crítico.

\section{Referencias bibliográficas}

ABEL, Günter (2001): "Bewusstsein-Sprache-Natur: Nietzsches Philosophie des Geistes", en Nietzsche-Studien: Internationales Jahrbuch für Nietzsche Forschung, 30, 1-43.

BABICH, Babette (2012): "Nietzsche's Post-Human Imperative: On the 'All-too-Human' Dream of Transhumanism", in The Agonist. Vol. IV, Issue II.

BOSTROM, Nick (2008): "Why I want to be a Posthuman when I Grow Up", in Medical Enhancement and Posthumanity, eds. Bert Gordijn and Ruth Chadwick, Springer, págs. 107-137.

BRAIDOTTI, Rosi (2013 / 2015): Lo Posthumano, Gedisa, Barcelona.

CHALMERS, David; CLARK, Andy (1998), “The Extended Mind”, in Analysis, 58: 1, págs. 7-19.

ELSTER, Jon (1991): Domar la suerte, Paidós Ibérica, Barcelona.

2005), en la que el autor nos va desgranando de un modo perfectamente lógico las catastróficas consecuencias, tanto individuales como sobre todo sociales y políticas, de lo que sería un estado de "muerte suspendida". Saramago viene a demostrar de nuevo, a su manera, que sin la muerte la vida se torna sencillamente invivible, un auténtico infierno en la Tierra.

22 Cf. Severino, E. (1982), Esencia del nihilismo, Madrid, Taurus, 1991. 
FREUD, Sigmund (1970): "Consideraciones de actualidad sobre la guerra y la muerte", en El malestar en la cultura. Alianza Editorial, Madrid, págs. 96-124.

FREUD, Sigmund (1999): El malestar en la cultura, Biblioteca Nueva, Madrid.

GREY, A. de y RAE, M. (2008): Ending Aging: The Rejuvenation Breakthroughs that could reverse Human Aging in Our Lifetime, St. Martin's Press, New York.

KURZWEIL, Ray (2005): The Singularity is Near. When Humans Transcend Biology, Viking Penguin, London.

NIETZSCHE, Friedrich (1972): La genealogía de la moral, Alianza Editorial, Madrid.

NIETZSCHE, Friedrich (1980): Sämtliche Werke. Kritische Studienausgabe in 15 Bänden hgn. von G. Colli und M. Montinari, Walter de Gruyter, Berlín / Nueva York.

NIETZSCHE, Friedrich (2006): Fragmentos Póstumos IV, edición dirigida por Diego Sanchez Meca, Tecnos, Madrid.

NOË, Alva (2004): Action in Perception, MIT Press.

PARFIT, Derek (1984 / 2004)): Razones y personas, Antonio Machado Libros, Madrid.

SARAMAGO, José (2005): Las intermitencias de la muerte, Alfaguara, Madrid.

SEVERINO, Emanuele (1982 / 1991): Esencia del nihilismo, Taurus, Madrid.

SORGNER, Stefan Lorenz (2009): "Nietzsche, the Overman, and Transhumanism", in Journal of Evolution and Technology, vol. 20, Issue 1, 29-42 págs.

SORGNER, Stefan Lorenz (2010): "Beyond Humanism: reflections on Trans- and Posthumanism", in Journal of Evolution and Technology, vol. 21, Issue 2, 1-19 págs.

SORGNER, Stefan Lorenz (2016): Transhumanismus - “die gefährlichste Idee der Welt"!?, Herder, Freiburg, Basel und Wien.

TUNCEL, Yunus (2017) (ed.): Nietzsche and Transhumanism, Precursor or Enemy?, Cambridge Scholars Publishing, Newcastle.

VARELA, Francisco Javier; Thomson, Evans; and Rosch, Eleanor (1991): The Embodied Mind. Cognitive Science and Human Experience, MIT Press.

VOGEL, Beatrix (2014) (hrgn.): Umwertung der Menschenwürde-Kontroversen mit und nach Nietzsche. Karl Alber, Freiburg / München. 
